\title{
MERCENARIOS Y CLASES DEPENDIENTES EN EL IMPERIO ESPARTANO: UN CAPÍTULO DE HISTORIA SOCIAL
}

\author{
MERCENARIES AND DISENFRANCHISED CLASSES IN THE SPARTAN EMPIRE: \\ A CHAPTER OF SOCIAL HISTORY
}

POR

CÉSAR FORNIS*

\section{RESUMEN - ABstract}

Esparta fue el primer Estado griego en hacer un uso masivo de mercenarios extranjeros. Al mismo tiempo, a nivel interno recurre al servicio militar de los hilotas, que alcanzarán la libertad pero no la ciudadanía. Ambos desarrollos se relacionan con el esfuerzo militar continuo exigido por el proyecto de construcción imperial espartano. Por otro lado, muchos lacedemonios que no pertenecían a la clase dominante de los homoioi pero que, sin embargo, habían sido adiestrados en el uso de armas, abandonaron Esparta para trabajar como soldados de fortuna aprovechando las posibilidades que la influencia del imperio ofrecía en varias regiones de importancia geoestratégica, lo cual suponía una especie de válvula de escape que aliviara la tensión sociopolítica en Laconia. De esta forma, mercenarios espartanos y mercenarios al servicio de Esparta son dos procesos imbricados y que corren en paralelo durante la vigencia del imperio espartano, desde la guerra del Peloponeso hasta la batalla de Leuctra.

Sparta was the first Greek state to make massive use of foreign mercenaries. At the same time, domestically it draws upon helots to military service; they become free but not citizens. Both processes are related to the continued military effort demanded by the Spartan empire-building project. On the other hand, many Lacedaemonians who did not belong to the ruling class of the homoioi but had nevertheless been trained in the use of arms left home to work as soldiers of fortune, taking advantage of the possibilities that the empire's influence afforded in various regions of geostrategic importance; it also provided a kind of safety-valve to relieve some of the building tension in Laconia. So, Spartan mercenaries and mercenaries for Sparta are two faces of the same coin: they are inherent and run in parallel during the several decades of the Spartan empire, from the Peloponnesian War to the Battle of Leuctra.

\section{Palabras Clave - Keywords}

Esparta; mercenarios; clases dependientes; imperio espartano.

Sparta; mercenaries; disenfranchised classes; Spartan empire.

\section{CÓMO CITAR ESTE ARTículo / CitATION}

Fornis, C. (2021): «Mercenarios y clases dependientes en el imperio espartano: un capítulo de historia social». Gladius, 41: 7-23. https://doi.org/10.3989/gladius.2021.01

\footnotetext{
"Universidad de Sevilla, cfornis@us.es / ORCID iD: https://orcid.org/0000-0002-9389-6592
} 
El mundo griego conocía el mercenariado desde al menos el siglo VII a. C., aunque por lo general bastante limitado a regiones periféricas y a los imperios del Próximo Oriente. Fue sin duda a partir de la guerra del Peloponeso, que supuso un punto de inflexión en las prácticas militares griegas, cuando este fenómeno tuvo una auténtica eclosión, con gran trascendencia en las estructuras de la polis posclásica ${ }^{1}$. Junto a la creciente introducción de infantería subhoplítica, cada vez más efectiva y valorada, el mercenariado contribuirá significativamente a la crisis del modelo de hoplita-ciudadano-propietario, es decir, de la identificación entre ciudadano terrateniente con plenos derechos políticos y hoplita defensor de los intereses y la autonomia de su polis. No menores fueron los efectos económicos, ya que se precisaban enormes recursos financieros para afrontar la contratación - y en ocasiones el sostenimiento- de mercenarios en gran número durante un período prolongado de tiempo.

Incluso siendo el paradigma de Estado hoplítico, Esparta va a participar activamente en este proceso; de hecho, los espartanos fueron los primeros en utilizar mercenarios a gran escala en su proyecto de construcción imperial. Al mismo tiempo muchos lacedemonios que no pertenecían a la clase dirigente de los homoioi, pero bien formados en el dominio de las armas, encontraron en el servicio como soldados de fortuna en el exterior una profesión que garantizaba su subsistencia y, en algunos casos, podía ser muy rentable. Los espartiatas mismos tenían prohibido por las leyes de Licurgo servir en el exterior si no era como miembros del ejército cívico (X. Lac. 14.4; Arist. fr. 543 Rose; Pl. Prt. 342D; Isoc. XI 18; Nic. Dam. FGrH 90F103z 5; Plu. Lyk. 27.6, Agis 11.2 y Mor. 238D). Ellos eran profesionales de la guerra, "artesanos" en la techne de Ares (X. Lac. 13.5; cf. Isoc. VI 81; Plu. Ages. 26.4-5 y Pelop. 23.3), pero no mercenarios, en un siglo IV en que la frontera entre unos y otros se hace cada vez más difusa ${ }^{2}$. Los espartiatas sí comandaron, sin embargo, con-

\footnotetext{
${ }^{1}$ Rop, 2019: 1 n. 2 recoge la bibliografía pertinente, con alguna notoria excepción a la communis opinio ( $v$. gr. Luraghi, 2006: 23: «las precondiciones reales para la existencia de mercenarios griegos en el siglo IV no eran muy diferentes de las del VII»).

${ }^{2}$ Como ha subrayado Yvon Garlan (en Marinovic, 1988: $\mathrm{v}$-vi), en el siglo IV se produce una cierta profesionalización de los ejércitos cívicos — desde la centuria anterior los ciudadanos reciben una paga por su servicio- y se generaliza la creación y mantenimiento de cuerpos de elite, hasta el punto de
}

tingentes de mercenarios extranjeros, en calidad de xenon stratiarchoi, ya fuera en expediciones propias o de sus aliados ${ }^{3}$.

El propósito del presente artículo es analizar el papel de los mercenarios espartanos y de los mercenarios al servicio de Esparta durante las décadas de su acme en la Hélade, desde la guerra del Peloponeso hasta la batalla de Leuctra, sin perder de vista en todo momento los cruciales cambios internos - especialmente socioeconómicos-que vive el Estado lacedemonio en dicho período; la contribución militar de los mercenarios y de las clases dependientes lacedemonias será instrumental para sostener durante un tiempo el diseño imperial, pero fue solo una solución parcial que no evitó el desmoronamiento de la arche espartana.

El primer empleo importante de mercenarios por parte de Esparta tuvo lugar durante la primera década de la guerra del Peloponeso, la llamada guerra arquidámica. Ya en 426 Tucídides (III 109.2) alude a «una masa de mercenarios» (ó $\mu 1 \sigma \theta 0 \varphi$ ópos ö $\chi \lambda \circ \varsigma$ ) sirviendo - junto al contingente regular de hoplitas mantineos- bajo el mando del espartiata Euríloco en la campaña de Acarnania, posiblemente reclutados en la región y pagados por los ambraciotas. Pero de lejos mucho más trascendentes fueron las campañas de Brásidas en la Calcídica tracia. En un momento crítico para Esparta, en el verano de 424 las autoridades lacedemonias deciden enviar una expedición al norte, a la lejana Calcídica, donde el imperio ateniense tenía intereses vitales. Es nombrado comandante de la expedición el audaz y carismático Brásidas, que había ganado fama en la guerra arquidámica pese a no pertenecer a ninguna de las dos casas reales (Agíadas y Euripóntidas). Según Tucídides, los protoi andres de Esparta le miraban con una mezcla de recelo y envidia ( $\varphi \theta$ óvo $\varsigma$ ), por ser enérgico ( $\delta \rho \alpha \sigma \tau \eta ́ p ı s)$ ), razón por la cual no pusieron a su disposición más que setecientos hilotas y mil mercenarios peloponésicos (Th. IV $70.1,80.5)$ y ni siquiera cuando hubo obtenido varios logros le fueron enviados los refuerzos que solicitó (IV 81.1, 108.7; sí contó con ayuda de aliados de la región: IV 102.1). La lejanía del teatro y la relativa independencia con la que opera, junto a la naturaleza de las tropas a su mando,

\footnotetext{
que habla, aunque con prudencia y sin forzar en exceso, de mercenaires de l'intérieur.

3 Trundle, 2004: 156-157, enfatiza que tal hecho no los convierte a ellos en mercenarios.
} 
prefiguran de algún modo en Brásidas la figura del condottiero, familiar en la Grecia del siglo IV.

Por primera vez en esta guerra hegemónica los lacedemonios se apartaban de lo que había sido su estrategia "convencional", consistente en anuales invasiones del Ática por el ejército hoplítico de la liga del Peloponeso, conducido por uno de sus diarcas. Se trataba sin duda de una maniobra inteligente, inesperada en los espartanos, que trataba de sacar partido de la insurrección de los aliados continentales de Atenas, dado que las islas les estaban vedadas por el control ateniense del $\mathrm{Egeo}^{4}$. Y lo que es más importante, se preservaban valiosas vidas espartiatas - ahora que Atenas mantenía como rehenes a los prisioneros de Esfacteria, agravando ese mal endémico y galopante que era la oliganthropia, la escasez de ciudadanos de pleno derecho ${ }^{5}$-, e incluso las de hoplitas aliados, que no conviene arriesgar en escenarios periféricos, extrapeloponésicos. En su lugar, Esparta utilizaba por primera vez a hilotas como mano de obra militar, armados como hoplitas y no como infantes ligeros, algo insólito, tanto por el temor atávico a la sublevación hilota como por la dificultad de entrenar en el armamento y las tácticas hoplíticas a esclavos que desconocían todo acerca de ellas. Además de conseguir soldados sin otro coste económico que las panoplias hoplíticas obviamente pagadas por el Estado-, servía como válvula de escape para la tensión interna que se vivía en Laconia, donde poco antes, según el escalofriante testimonio de Tucídides (IV 80.2-4; cf. D.S. XII 67.4), dos mil hilotas seleccionados habían sido exterminados después de engañarlos con la promesa de liberación. Tucídides es firme en su conclusión de que la mala situación por la que atravesaban los lacedemonios en su patria fue determinante para que un ejército suyo saliera del Peloponeso (IV 79.3).

Junto a estos hilotas figura una fuerza de un millar de mercenarios reclutados por Brásidas

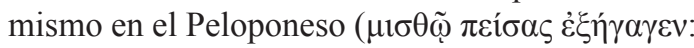
Th. IV 80.5), si bien no hay seguridad de que tal paga fuera abonada por los espartanos mismos, que, cabe recordar, no tenían tesoro propio ni de la liga del Peloponeso (Th. I 80.4) ni recibían aún

\footnotetext{
${ }^{4}$ Hunt, 1998: 58.

${ }^{5}$ Sobre las causas, y también las consecuencias, de la oliganthropia en la sociedad espartiata tenemos la recentísima monografía de Timothy Doran, 2018, que además revisa las distintas interpretaciones historiográficas modernas.
}

subsidios persas ${ }^{6}$. Se ha señalado la posibilidad de que el estipendio corriera a cargo de Perdicas II de Macedonia y de los calcidios rebelados contra Atenas ${ }^{7}$, dado que habían sido ellos quienes habían solicitado la ayuda espartana movidos por sus propios intereses: el macedonio quería someter a Arrabeo, rey de los lincestas, y los calcidios sublevados temían ser el primer objetivo de las represalias atenienses (Th. IV 79.2, 83); pero lo cierto es que Tucídides solo habla de mantenimiento del ejército, que puede referirse exclusivamente a las raciones de comida del conjunto de las tropas, no solo de los mercenarios, y vuelve a hacerlo cuando Perdicas, ofendido por el acuerdo alcanzado entre Brásidas y Arrabeo, reduce de la mitad a un tercio su contribución a dicho

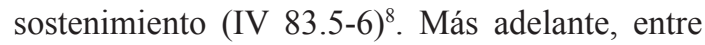
los distintos contingentes aliados que luchan con Brásidas en Anfípolis, Tucídides identifica como mercenarios a 1500 tracios (V 6.4), pero podemos preguntarnos si todos o algunos de los peltastas calcidios, edones y mircinios también lo eran.

Aunque social e ideológicamente infravalorados, los hilotas y los mercenarios de Brásidas infligieron un severo daño en esta sensible área geoestratégica de la arche ateniense. Brásidas utilizó a los mercenarios peloponesios con diferentes fines: primero, para el combate stricto sensu incluso contra los bárbaros lincestas e ilirios-, segundo, para someter a pillaje los campos y bienes extramuros de las ciudades a fin de empujar a sus habitantes a abandonar la alianza ateniense - se muestra muy efectivo en Anfípolis-, y tercero, como guarniciones para proteger ciudades - destina 500 a la defensa de Esción y Mende, al mando de un oficial espartiata, Polidamidas - o

\footnotetext{
${ }^{6}$ Ya lo reconoce el rey Arquidamo II en Th. I 80.4: «no tenemos dinero en el tesoro público ni estamos en condiciones de obtenerlo fácilmente de los recursos privados». En su crítica al ordenamiento constitucional lacedemonio, Aristóteles (Pol. 1271b10-17) señala que el tesoro público está vacío y su sistema tributario es ineficaz, por no decir inexistente.

${ }^{7}$ Así English, 2012: 46. Parke, 1930: 40 (cf. Parke, 1933: 16), ya contemplaba tal posibilidad, pero añadía la promesa del botín de campaña y que, en caso de emergencia, podría alquilar su ejército, es decir, lo mismo que haría un comandante mercenario del siglo IV. Según Valzania, 1999: 99, toda la expedición la pagaron los corintios (mercenarios, armas, víveres, dinero en efectivo y lo que se precisara), sin citar ninguna fuente ni explicar en qué fundamenta tal hipótesis. Hodkinson, 2000: 168, da por sentado que fue financiada por Esparta, sugiriendo (cf. 187-188) algún tipo de tasación sobre el cuerpo cívico.

${ }^{8}$ Prichett, 1971: 46.
} 
pequeños enclaves. En apenas un año, gracias a su diplomacia armada, Brásidas se hizo con el control de dos de las tres penínsulas que configuran la Calcídica tracia, Acte y Sitonia -incluyendo Anfípolis, la colonia fundada por los atenienses en la desembocadura del río Estrimón, que suministraba importantes ingresos y madera para construcción naval-, mientras la restante, Palene, continuaba sujeta al imperio ateniense (Th. IV 78$88,102-116)$. Se produce así un punto de inflexión en un conflicto que gira desde la derrota espartana hacia la paz de Nicias. En recompensa por su servicio, estos hilotas - conocidos en adelante como Brasideioi - recibieron la libertad, lo que supuso abrir por primera vez una vía de integración parcial de esta población servil que, sin embargo, nunca llegó a formar parte del cuerpo cívico, del politeuma lacedemonio?.

Durante el resto de la guerra del Peloponeso hubo comandantes lacedemonios dirigiendo tropas mercenarias terrestres, tanto infantes pesados como ligeros, pero estas nunca fueron pagadas por Esparta, sino por aliados. Sin embargo, en la última fase del conflicto, la llamada guerra jónica, Esparta contrató gran número de remeros para la nueva flota construida y mantenida gracias a los ilimitados recursos persas. Igual que había sucedido en tierra, Esparta recurre a la prestación militar en las naves de las clases dependientes: junto a los nautai mercenarios, la participación de hilotas en los remos llegará a ser imprescindible para su operatividad (cf. X. HG. V 1.11; VII 1.12) ${ }^{10}$. A los problemas de financiación que requiere una armada numerosa - de los que los espartanos tardan en tomar conciencia ${ }^{11}$ - , se añadía el hecho de que ni ellos ni sus aliados peloponésicos tenían experiencia en navegación, de modo que conforme se prolongaba la guerra contra Atenas la clase dirigente espartiata fue superando paulatinamente

9 De hecho, junto a un grupo de neodamodeis (vid. infra), en 421 fueron instalados en Lépreo, en territorio disputado a los eleos, no está claro si como guarnición o como colonos paramilitares (Th. V 34.1). Cozzoli, 1978: 222, identifica a los

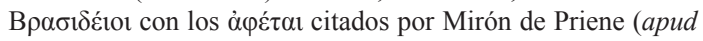
Ath. 251F).

${ }^{10}$ Mucho más dudosa es la participación de periecos como remeros, mientras carece de sentido especular sobre los enigmáticos desposionautai a partir de una mención aislada en Mirón (ibid.), más allá de que debían de ser esclavos liberados que cumplían algún tipo de servicio en la flota. Sobre estas cuestiones, véase Welwei, 1974: 158-161; Sealey, 1976; Bertosa, 2005 (bastante especulativo).

11 Kallet, 2001: 126, 246, 256-259, 271, 278, 280, 297. sus discrepancias internas acerca de la cuestión de si era conveniente negociar con el bárbaro y decidió al fin pagar un precio político a cambio del oro persa: el reconocimiento de la soberanía del Gran Rey sobre los griegos de Asia Menor (Th. VIII 18, 37, 58). Con todo, en los primeros años de la guerra jónica los pagos persas no fueron ni fluidos ni regulares ni completos, debido a que el sátrapa Tisafernes no estaba dispuesto a sacrificar sus propios recursos privados, llegándose incluso a producir amotinamientos de la marinería, como el que sufrió el navarco (almirante) Astíoco en la base de Mileto en 411 (Th. VIII 29, 36.1, 45.2 y 6, 57.1. 58.5-6, 78, 80.1-2, 83-85.1) ${ }^{12}$.

Por otro lado, si una inscripción única encontrada en Esparta ( $I G \mathrm{~V}$ 1.1) puede ser asignada con cierta seguridad a este período, como apuntan los estudios más recientes ${ }^{13}$, significaría que los espartanos exigieron contribuciones de los aliados disconformes con Atenas, expresadas en dáricos persas, que ayudaran a sostener el esfuerzo bélico en el Egeo. Tucídides recoge en una ocasión cómo los espartanos demandan a los rodios 32 talentos, algo menos de lo que pagaban a Atenas (VIII 44.4). Esta medida de coerción no se aplicó, sin embargo, a los Estados miembros de la liga del Peloponeso, que seguían sin pagar nada (Th. I 19). Los lacedemonios asumieron la realidad de que Atenas solo podría ser derrotada en su medio, en el mar, y como los espartiatas no iban a emplearse en los remos, tendrían que hacerlo hilotas y nautai mercenarios.

La colaboración entre Esparta y Persia se intensificará y adquirirá mayor consistencia desde 407 , fecha en que es nombrado navarco de la flota peloponésica el espartiata Lisandro. Lisandro enseguida estableció fuertes vínculos personales, fundados en la xenia o amistad ritualizada, con Ciro el Joven, el hijo pequeño del rey Darío II; nombrado karanos, con mando supremo de las tropas reales persas en la península anatólica (X. $H G$. I 4.4; III 2.13; cf. D.S. XIV 26.4; Nep. Ages. 2.3), la misión principal de Ciro era canalizar toda la política persa en el occidente de su imperio. Esto se traducirá en asiduas, regulares y sustanciosas entregas de dinero a los espartanos, que incluso se permitieron pagar a las tripulaciones de sus naves una soldada superior — cuatro óbolos diarios-

12 Hyland, 2018: 53-97, detalla el contexto persa de estos acontecimientos.

13 Loomis, 1992; Bleckmann, 1993, 2002; Piérart, 1995. 
a la percibida por las del imperio ateniense, que desde el fracaso de la expedición a Sicilia era de un trióbolo (X. HG. I 5.1-7; II 1.10-15) ${ }^{14}$. En palabras de Lengauer, «Lisandro construyó su posición sustentándola en mercenarios» ${ }^{15}$.

Durante su año de mandato, Lisandro obtuvo la victoria sobre la flota ateniense en Notio, en la primavera de 406, no demasiado importante estratégica y militarmente - los atenienses solo perdieron quince naves - , pero que sí deparó una consecuencia política: la caída en desgracia de Alcibíades (X. $H G$. I 5.10-18). A Lisandro le sucede en el cargo Calicrátidas, cuyo espíritu menos pragmático soportaba mal la dependencia de los subsidios persas y todavía peor las humillaciones que le infligía Ciro, por ejemplo haciéndole esperar dos días antes de recibirle. En agosto de 406 Calicrátidas sufrió una grave derrota frente a la flota ateniense en las islas Arginusas, durante la cual el almirante cae al mar y desaparece (X. $H G$. I 6.24-35). Dicho fracaso, unido a otro conato de motín de las tropas por el retraso en la paga — que casi acaba con el saqueo de Quíos y que suscitó la indignación de los aliados - y a una petición expresa de los embajadores persas, convencieron a los lacedemonios de la necesidad de colocar a Lisandro otra vez al mando de las operaciones en Asia Menor, ahora en calidad de epistoleos (X. HG. II 1.6-7; Plu. Lys. 7.2-3). Nuevas transferencias de dinero por parte de Ciro permiten a Lisandro construir naves en Antandro, reunir y aparejar las antiguas y pagar a los marineros los sueldos atrasados (X. HG. II 1.10-12, 14-15). A finales del verano de 405, después de capturar y saquear Lámpsaco, Lisandro decidirá la suerte de la guerra muy cerca de esta ciudad, en un lugar llamado Egospótamos, donde sorprende a las naves atenienses varadas en tierra y a sus tripulaciones dispersas, de forma que se apoderó de la práctica totalidad de los ciento ochenta trirremes y ejecutó a todos los prisioneros de origen ateniense (X. $H G$. II 1.18-32; D.S. XIII 105-106 muestra divergencias).

Podemos concluir, por tanto, que durante la guerra del Peloponeso Esparta hizo un uso desigual de tropas mercenarias, condicionada por sus escasos recursos financieros y por los problemas inherentes a su sociedad (la escasez de ciudadanos

${ }^{14}$ Hyland, 2018: 107-121, incluyendo una estimación general de los subsidios persas a las distintas flotas peloponésicas desde 412 a 404.

15 Lengauer, 1979: 80. y el peligro hilota). En la primera fase de la contienda la utilización de mercenarios - de origen peloponésico - fue marginal, limitada a expediciones terrestres en áreas muy alejadas del epicentro de su imperio, el Peloponeso. Por el contrario, en la guerra jónica las sucesivas inyecciones de dinero persa posibilitaron la contratación masiva de mercenarios como remeros para la flota, provenientes en su mayor parte de las islas del Egeo y la costa minorasiática.

La victoria sobre la arche ateniense tuvo como consecuencia la instauración de un nuevo orden internacional por parte de Esparta, que a su imperio continental añadía ahora otro marítimo y nuevas e importantes fuentes de recursos (solo el botín enviado a casa por Lisandro ascendía a mil talentos según Plu. Nic. 28.3, que cita a Timeo; mil quinientos según D.S. XIII 106.8-9, basado en Éforo). Esparta comenzó, además, a exigir tributo de una manera regular, al menos en las islas y en las regiones costeras de Asia Menor, solo que reviste el nombre de synteleia en lugar del reprobado término de phoros (Isoc. IV 132; XII 67-68; Arist. AP. 39.2 y fr. 544 Rose; D.S. XIV 10.2, basado en Éforo, es la única fuente en cifrar la recaudación anual, más de mil talentos, pero parece exagerada). Estos nuevos medios de financiación incrementaron exponencialmente las posibilidades de explotación de la mano de obra mercenaria, abundante como consecuencia de: 1) la desmovilización de tropas producida por el final de la contienda, 2) la masa de campesinos empobrecidos que habían perdido o habían visto arrasadas sus tierras y/o cosechas, así como trabajadores manuales en las ciudades que habían quedado sin empleo, 3) los numerosos exiliados y refugiados que habían generado las staseis en el interior de las ciudades alimentadas por la lucha hegemónica, 4) la situación de beligerancia continuada que va a caracterizar a buena parte del siglo $\mathrm{IV}^{16}$. En paralelo Esparta potencia el aprovechamiento militar de sus propias clases dependientes, numerosas y heterogéneas. Ambas medidas intentan dar respuesta a la inadecuación entre el reducido número de homoioi y los ambiciosos proyectos imperiales de los mismos (o al menos

${ }^{16}$ Parke, 1933: 18, 68; Lengauer, 1979: 89; Miller, 1984: 154; Marinovic, 1988: 26, 34-35; Tourraix, 1999: 205; English, 2012: 52; Ducrey, 2019: 314. Contra Roy, 1967: 321323 (reafirmado en Roy, 2004: 267), que no cree que la guerra del Peloponeso contribuyera al aumento de la profesionalización militar. 
de una parte significativa de los que participan en los resortes de poder).

Asia Menor será un escenario clave de la intervención espartana, que en principio no se produce de manera directa, pero que irá progresivamente adquiriendo mayor calado y consistencia. Con el propósito de contestar el derecho al trono de su hermano mayor Artajerjes II, Ciro el Joven organizó en 401 la mayor expedición de mercenarios griegos conocida hasta entonces - los llamados Diez Mil o cireos, entre los que se encontraba el historiador Jenofonte, narrador de sus aventuras y desventuras en la Anábasis - a los que acompañaba un ejército local integrado por unos veinte mil anatolios y griegos minorasiáticos; los mercenarios se adentraron en el corazón del imperio persa y combatieron en Cunaxa, cerca de Babilonia, obteniendo una victoria a la que la muerte de su protector y pagador privó de significado.

Prima facie la expedición no marchó bajo ninguna bandera ni contó con la sanción oficial de ningún Estado griego, pero la implicación lacedemonia es tan clara como para hacer creer a Isócrates (XII 104; cf. VIII 98 y Plu. Artx. 6.5) y a Éforo (FGrH 70F70 apud D.S. XIV 11.2; cf. 19.4) que los espartanos conspiraron con Ciro y prepararon la empresa para él. Para empezar, el primer comandante en jefe de los aproximadamente 13000 mercenarios cireos - 10400 hoplitas y 2500 peltastas - fue el espartano Clearco. Había sido condenado a muerte in absentia en Esparta por desobediencia durante su mando en el Helesponto - se había erigido en tirano de Bizancio con el respaldo de numerosos mercenarios contratados para la ocasión-, tras lo cual pasó a la corte de Ciro y, ganándose su admiración y su confianza, le puso al mando de los "Diez Mil" (D.S. XIV 12). Sin embargo, según algunas fuentes servía en realidad a los intereses de Esparta (Isoc. VIII 98; en Plu. Artx. 6.5 recibe órdenes de los éforos a través de la escítala); si no fue así, al menos Esparta no dificultó en modo alguno la labor de reclutamiento y de dirección del ejército mercenario por parte de Clearco. Jenofonte (An. II 6.1-15) compone un vívido retrato literario de Clearco ${ }^{17}$, lo define como «un hombre verdaderamente amante de la guerra (polemikos kai philopolemos)», que no sabía (o no quería) vivir en paz, partidario de que los hombres le temieran más que al enemigo, una

17 Bettalli, 2013: 297-302; véase asimismo Bassett, 2001: esp. 7-12, para la etapa de su vida que aquí contemplamos. severidad que se tornaba firmeza y confianza en el combate, razón por la cual sus hombres lo preferían en momentos difíciles, pero lo abandonaban una vez pasado el peligro si podían seguir a otro. Clearco parece ser el producto esperado de una sociedad como la espartana que transpira guerra por los cuatro costados. Otro producto lacedemonio - inacabado - que emerge en la Anábasis fue Dracontio, huido de niño de su patria por haber matado accidentalmente con un cuchillo a otro muchacho (IV 8.25).

Sin duda relevante es el hecho de que muchos de los cireos provinieran del Peloponeso, el epicentro del imperio espartano, convertido en auténtico centro de reclutamiento de mercenarios abierto a los aliados, previo consentimiento de los éforos ${ }^{18}$. No es casualidad que los intereses de estos mercenarios peloponésicos acostumbren a coincidir con los de sus empleadores, beneficiarios de la alianza o la amistad con Esparta ${ }^{19}$. Setecientos cireos eran además lacedemonios (800 según Diodoro), al mando de Quirisofonte, a quien Jenofonte (An. I 4.3) presenta como respondiendo a vínculos de xenia o philia con Ciro, es decir, de la misma naturaleza que los forjados con Lisandro. Quirisofonte sería más tarde comandante en jefe de los Diez Mil, en detrimento de un Jenofonte al que habían elegido los propios soldados, pero que renunció por ser consciente de que la jefatura de un espartano lubricaría las relaciones con los harmostas representantes del nuevo poder hegemónico en el Egeo (X. An. VI 1.25-33); otro strategos lacedemonio, en este caso un perieco de Asine llamado Neón, también pensó que alcanzar el Quersoneso y ponerse bajo el control espartano le ayudaría en su aspiración de liderar en solitario a los mercenarios (X. An. VII 2.2). Como ha seña-

\footnotetext{
18 Es idea ampliamente aceptada en la historiografía moderna que, según avanza el siglo IV, el promontorio del Ténaro, al sur de Laconia, se afianza como uno de los grandes mercados de contratación de mercenarios del Mediterráneo oriental, pese a que haya sido desafiada recientemente por Couvenhes, 2008. Trundle, 2004: 106-107, 157 y Millender, 2006: 246, destacan el papel de los dirigentes espartanos como intermediarios entre los mercenarios y sus empleadores, fundamentalmente a través de vínculos de clase; sin embargo, esto no es una «fuerte evidencia», para considerar, como Rop, 2019: 79, que «el príncipe usaba la xenia para extender la influencia imperial de Persia en Grecia»; el norteamericano sobrevalora la capacidad persa para condicionar de esta manera la escena política en Esparta y sus Estados aliados y, lo que es peor, acaba por decir (p. 84) que los cireos no eran mercenarios, sino aliados.

19 Según Trundle, 2004: 43, 71 «estaban cumpliendo obligaciones de la liga del Peloponeso».
} 
lado Trundle, la procedencia lacedemonia era una evidente fuente de autoridad sobre mercenarios ${ }^{20}$. A ello cabe añadir el apoyo logístico provisto por Esparta desde el mar a través de su navarco Samio durante la marcha a Babilonia (X. HG. III 1.1-2; D.S. XIV 19.4-5). Ellen Millender ha sugerido incluso que las autoridades espartanas pudieron mantener un cierto control de la expedición ${ }^{21}$. Lo que puede decirse con seguridad, a partir del rol jugado por los altos oficiales espartanos, es que al menos no la desaprobaban ${ }^{22}$. Pero en sustancia y en cuanto a intereses personales, los 700 hoplitas lacedemonios no eran diferentes del resto de los mercenarios griegos enrolados en el ejército de Ciro (las motivaciones de los cireos son enumeradas en X. An. VI 4.8 ${ }^{23}$. Simplemente el príncipe persa valoraba en mayor medida la competencia y la experiencia ( $\left.\dot{\varepsilon} \mu \pi \varepsilon 1 \operatorname{pí}^{\alpha}\right)$ de los hoplitas peloponésicos (X. An. I 1.6) y, dentro de estos, de los lacedemonios (cf. Th. IV 33.2), incluso si no eran homoioi.

$\mathrm{Y}$ es que los únicos espartiatas de pleno derecho que comparecen en la narrativa jenofóntica son los harmostas y navarcos, investidos de la autoridad estatal, mientras que los lacedemonios integrantes de los Diez Mil, salvo en todo caso Quirisofonte, no tienen la ciudadanía plena, son una suerte de "desclasados" a los que se aplican eufemismos como "ciudadanos incompletos", "ciudadanos parciales" o "ciudadanos de segunda" (no dejan de ser perífrasis modernas que no definen con propiedad su lugar en el kosmos sociopolítico espartano). En primer lugar, exiliados y periecos, algunos de los cuales son mencionados explícitamente (Clearco y Dracontio, entre los primeros; Dexipo y Neón entre los segundos). Después seguramente habría también muchos vं

\footnotetext{
${ }^{20}$ Trundle, 2004: 137.

${ }^{21}$ Millender, 2006: 239-245, quien no obstante reconoce (243) que no faltaron momentos de tensión e incluso de hostilidad de los harmostas espartanos hacia los mercenarios tras la muerte de Ciro. Hodkinson, 2000: 349, Hyland, 2018: 126 y Rop, 2019: 78, ven un carácter oficial en la ayuda espartana a Ciro. Tourraix, 1999: 205, parece sugerirlo también. Contra Roy, 1967: 308: The large number of Spartans is probably misleading ... It therefore seems that the apparent importance of Spartans on the Anabasis is accidental.

${ }^{22}$ Roy, 1967: 300, Cartledge, 1987: 320 y Bettalli, 2013: 281-284, prefieren hablar de connivencia espartana, porque la evidencia presentada por Jenofonte no permite ir más allá. Cf. Lewis, 1977: 138.

${ }^{23}$ Roy, 1967: 300; 2004: 266; Tourraix, 1999: 206.
}

habían sido excluidos del cuerpo cívico por no poder aportar a los syssitia las raciones estipuladas de alimentos, según la definición aristotélica (Pol. 1271a26-37; 1272a13-17), aunque probablemente habría que incluir entre ellos a todos aquellos que habían sido castigados con la pena de atimia, ya fuera por no haber superado la agoge, por no haber sido aceptados en ninguna mesa común o por haber quebrantado la diaita o código de conducta licurgueo, por ejemplo, mostrando cobardía en el combate (X. Lac. 3.3; 10.7). El aumento del número de hypomeiones durante el siglo IV está directamente relacionado con los desequilibrios económicos que conlleva la administración del imperio, el cual fomentó el enriquecimiento de determinados individuos que accedían a los mecanismos de poder y que después invertían esos beneficios en la compra de tierra a espartiatas empobrecidos ${ }^{24}$. Otro grupo que debió de estar presente en la expedición sería el de los mothakes, que se han educado junto a los hijos de los "iguales" en el marco de la agoge (Ath. 271E-F; Hesych. s.v. $\mu$ ó $\theta \alpha \kappa \varepsilon \zeta ;$ Ael. VH. XII 43) ${ }^{25}$, y quizá incluso el de los llamados trophimoi, extranjeros criados en Esparta $^{26}$; a propósito de la campaña olíntica del rey Agesípolis en 381, unos y otros son descritos

\footnotetext{
${ }^{24}$ Carlier, 1996

${ }^{25}$ La historiografía moderna tiende a ver en ellos a hijos bastardos (nothoi) nacidos de relaciones extraconyungales entre espartiatas o de uniones mixtas entre espartiatas e hilotas (Ehrenberg, 1939a; Lotze, 1962, que extiende este estatus a los hijos de los hypomeiones; Welwei, 1974: 131-134; MacDowell, 1986: 46-51, incluye en este grupo no solo a los hijos de los hypomeiones, sino también a los de los extranjeros, los trophimoi, e incluso plantea que, terminada la agoge, se convertirían en neodamodeis; Christien-Tregaro, 1993: 38; Ogden, 1996: 217-224), pero hay quienes creen que eran hijos exclusivamente de hilotas por tanto esclavos - que acompañaban a sus jóvenes amos en la agoge (Cozzoli, 1978: 224-231; Bruni, 1979: 23-24; Furuyama, 1991) y quienes opinan que se nutría tanto de hijos ilegítimos como de otros de origen hilótico (Ruzé, 1993: 301-302). Según Cartledge, 1987: 28, Hodkinson, 1997: 55-62; 2000: 355-356, y Ducat, 2006: 150-153, que parten de la tesis de Lotze (ibid.), asumirían esta condición los hijos de los espartiatas pobres, apadrinados en su educación por determinados oikoi pudientes, en una relación claramente de patronazgo. Para Paradiso, 1997: 8182 , en su mayoría tendrían un origen servil, pero no descarta que englobaran también a los hijos de los espartiatas empobrecidos.

${ }^{26}$ Son hijos de extranjeros de alta extracción social, con peso e influencia en sus respectivos Estados —o bien en el exilio por su militancia ideológica - y con vínculos de philia o xenia con influyentes personajes de la sociedad espartana (D.L. II 54; Plu. Ages. 20.2 y Phoc. 20.4). Véase: Ehrenberg, 1939b; Humble, 2004. Hodkinson, 1997: 62-65, y Ducat, 2006: 153155 , sugieren que los hijos de prominentes periecos laconios y mesenios también entrarían en la categoría de trophimoi.
} 
por Jenofonte ( $H G$. V 3.9) como «de muy buen aspecto y no inexpertos en los derechos y deberes de la ciudad». Estos y otros grupos dependientes, que probablemente podían proporcionarse su armamento y habían recibido formación y entrenamiento militar, fueron por lo general carne de mercenariado, aprovechando las posibilidades que los tentáculos del imperio proporcionaban en distintas áreas geoestratégicas ${ }^{27}$.

Con la muerte de Ciro y el regreso de Tisafernes a Jonia, algunas ciudades jonias apelaron a los lacedemonios para que, en calidad de «líderes

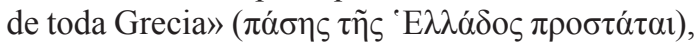
defendieran sus territorios y les devolvieran su libertad (X. HG. III 1.8). Los espartanos aprovecharon la reivindicación de autonomia de los jonios para disfrazar su Realpolitik (cf. Iust. VI 1.1) y dar legitimidad a su intervención directa en Asia Menor, en vulneración de los tratados acordados con el Gran Rey durante la guerra jónica ${ }^{28}$.

De esta forma, en el año 400 los éforos espartanos decretaron el envío a Asia de Tibrón como harmosta, acompañado de mil neodamodeis, cuatro mil aliados peloponesios y trescientos caballeros atenienses. Los $v \varepsilon o \delta \alpha \mu \omega ́ \delta \varepsilon ı \zeta$ eran hilotas liberados e integrados con restricciones en el cuerpo cívico. Aparecen por primera vez a finales de la guerra arquidámica, cuando el desastre de Esfacteria en 425 hizo necesario incorporar hoplitas al ejército lacedemonio (Th. V 34.1), mientras que son mencionados por última vez en el invierno del año 370/369 (X. HG. VI 5.24), es decir, poco después de la batalla de Leuctra, que señaló el comienzo del declive militar espartano. Este marco cronológico y el hecho de que solo aparezcan en contextos militares hacen que concibamos al neodamodes como una figura estrechamente ligada al período de hegemonía espartana en Grecia, en el que el esfuerzo bélico continuado obligaba a una ampliación de la ciudadanía, bien que limitada, a una parte de la población servil ${ }^{29}$. En este tiempo su número no deja de incrementarse y supera con mucho al de ciudadanos. Al mismo tiempo que se conseguía mano de obra militar, a bajo coste además, el Estado aliviaba la tensión

\footnotetext{
${ }^{27}$ Cozzoli, 1978: 220-231; Carlier, 1994: passim.

${ }^{28}$ Tan solo Lewis, 1977: passim, acepta como genuina la vocación panhelénica de Esparta.

${ }^{29}$ Willetts, 1954; Lotze, 1962; Welwei, 1974: 142-158; Alfieri Tonini, 1975; Cozzoli, 1978: 221-224; Bruni, 1979: 2628; Ruzé, 1993: 299-301; Carlier, 1994; Hunt, 1998: 170-175; Doran, 2018: 74.
}

interna generada por la población dependiente, pues los neodamodeis era destinados a campañas en escenarios bélicos muy distantes del territorio laconio, como estas de Asia Menor, o eran instalados como colonos con misiones de vigilancia y protección en guarniciones o en zonas fronterizas. Esto demuestra que, en la práctica, los neodamodeis eran soldados profesionales, bien entrenados, cuyo servicio apenas se podía distinguir del de los mercenarios en cuanto a que estaban libres de las "ataduras" a propiedades y cultivos que tenían ciudadanos y periecos ${ }^{30}$.

Una vez en suelo asiático, con Éfeso de base de operaciones para su campaña contra Tisafernes, Tibrón realizó levas locales entre las ciudades aliadas, dos mil jonios según Diodoro (X. HG. III 1.4-5; D.S. XIV 36.1-2); al año siguiente, tras tomar Pérgamo, contrató a cinco mil mercenarios veteranos de la campaña de Ciro, con un salario de un dárico mensual por soldado - el equivalente a veinte dracmas áticas, lo mismo que percibían con Ciro y que parece ser la paga media a comienzos del siglo IV $^{31}$-, el doble para los lochagoi y el cuádruple para los strategoi (X. HG. III 1.6; An. VII 6.1, 8.24; D.S. XIV 37.1).

El mero contraste de los amplios efectivos de los que dispuso Tibrón —en total 12300 hombres - frente a los mucho más limitados de Brásidas durante su expedición tracia de 424 ponen de manifiesto los cambios experimentados por Esparta en su proceso de expansión imperial: más medios económicos para alcanzar objetivos más $\operatorname{ambiciosos}^{32}$. Incapaz de que su reducido y exclusivista cuerpo cívico soporte el peso del nuevo imperio ultramarino y la aspiración a la hegemonía panhelénica, Esparta no solo se convierte en el primer Estado griego en recurrir al empleo masivo de mercenarios, sino que en el orden interno multiplica categorías y subcategorías sociales (neodamodeis, hypomeiones, desposionautai, tresantes, mothakes, nothoi, trophimoi, aphetai, adespotoi, erykteres) que tienen en común, por un lado, su marginación política y económica con respecto a los homoioi y, por otro, el aprovechamiento militar del que son objeto ${ }^{33}$. La organización militar

\footnotetext{
30 Hunt, 1998: 171.

31 Pritchett, 1971: 19-20; cf. Krasilnikoff, 1993: 95: entre $4 \frac{1}{2}$ y 6 óbolos al día durante la guerra del Peloponeso y la primera mitad del siglo IV.

32 Parke, 1933: 43.

33 Sobre la progresiva incorporación al ejército lacedemonio de estos grupos dependientes, véase: Cozzoli, 1978:
} 
lacedemonia se transforma a la vez que se transforma su sociedad, en un proceso de interacción continua que entraña sus riesgos, como queda patente en el famoso pragma de Cinadón (X. $H G$. III 3.4-11) apenas ascendido al trono euripóntida Agesilao II, que significó una amenaza cierta para el orden establecido de los homoioi ${ }^{34}$.

El año de mandato de Tibrón no solo estuvo yermo de cualquier logro estratégico —-más allá de la dominación de la Eólide septentrional y de la Misia pergamenea-, sino que además el harmosta se vio incapaz de controlar a sus hombres para que no sometieran a pillaje indiscriminado los territorios que atravesaban, buena parte de los cuales pertenecían a ciudades jonias aliadas de Esparta. Las quejas de los symmachoi se tradujeron en la imposición de una multa y el exilio de Tibrón apenas hubo regresado a Esparta (X. HG. III 1.8). La explicación es sencilla. A diferencia de lo que sucedió en la guerra jónica, Esparta no contaba ahora con los imprescindibles fondos persas para pagar con regularidad la soldada de tal cantidad de mercenarios durante un tiempo prolongado, de modo que el botín y el pillaje se convierten en los principales mecanismos de autofinanciación de esta clase de combatientes - no era diferente de lo que habían hecho para sobrevivir en Asia- y, de esta forma, dependerá en gran medida de las dotes de mando de su comandante el mantenimiento de la disciplina en condiciones adversas ${ }^{35}$; una consecuencia inevitable será el avance en el proceso de personalización del poder, de modo que el jefe militar, antaño mucho más sujeto a las directrices emanadas de la polis, disfrutará de tanto más poder cuanto más se gane la lealtad de sus hombres ${ }^{36}$.

A Tibrón lo sucede en el puesto Dercílidas, apodado "Sísifo" por su ingenio, que no solo pone coto a las tropelías de los cireos - el retrato jenofóntico lo muestra más atento a las necesidades de los mercenarios y así debió de ser cuando las Helénicas de Oxirrinco (21.2) se refieren a estos como los "dercilídeos" ${ }^{37}$-, sino que además sabe

220-231; Lazenby, 1985: 13-20, 60-62; Carlier, 1994; 1996; Hawkins, 2011; Doran, 2018: 74-76.

34 Fornis, 2007a

35 Bettalli, 2013: 151, ha calculado en aproximadamente mil talentos el coste de mantener a estos mercenarios durante los cinco años que estuvieron activos (399-394), sin contabilizar ni las bajas ni el sueldo más elevado de los oficiales.

36 Lengauer, 1979: 95-127; Marinovic, 1988: 39-43.

37 Parke, 1933: 44. Anderson, 1970: 303 n. 33, piensa en cambio que estos dercilídeos eran peltastas y no antiguos cireos. sacar partido de las rencillas personales entre Tisafernes y Farnabazo para asolar y saquear sucesivamente las satrapías de ambos. A requerimiento de las ciudades griegas del Quersoneso, los espartanos extienden en 398/397 su tutela hasta dicha región, que soportaba incursiones de los tracios, consiguiendo de paso tierras cultivables donde asentar colonos lacedemonios - extraídos de entre los grupos de no ciudadanos- que las defendieran. De nuevo en Asia, Dercílidas se apoderó de Atarneo, abundante en provisiones, y la dejó al cargo del perieco Dracón de Pelene. En Panegírico (144), Isócrates afirma que Dracón reunió una fuerza de tres mil peltastai, presumiblemente mercenarios ${ }^{38}$, con los que devastó las llanuras de Misia y proporcionó más movilidad a su ejército, contrarrestando la superioridad persa en este sentido. Dercílidas también empleó 300 peltastas tracios enviados por Seutes I para labores de pillaje en las que se apoderaban de muchos esclavos y bienes. Este saqueo sistemático de campos y ciudades capturadas - hasta nueve en ocho díassirvió tanto para la subsistencia diaria de sus miles de hombres como para afrontar la soldada de sus mercenarios, sin necesidad de recurrir a exacciones o al expolio de las ciudades asiáticas aliadas ${ }^{39}$. Después de penetrar en la más sensible Caria, en la primavera de 397 Dercílidas forzará una tregua ante las tropas conjuntas de Tisafernes y Farnabazo por la cual los persas respetarían la autonomía de las ciudades griegas de Asia Menor a cambio de la retirada del ejército lacedemonio; según el sesgado relato de Jenofonte, el karanos Tisafernes rehusó trabar combate en el último momento porque temía a los cireos y pensaba que todos los griegos eran como ellos (X. HG. III 1.3-2.20; D.S. XIV 35.1-38.3 ${ }^{40}$.

En la expedición que al año siguiente Agesilao II conduce a Asia Menor, acompañada de una notable propaganda que la reviste de elementos panhelénicos y con él mismo en el papel de un nuevo Agamenón, las fuentes no citan en principio la

${ }^{38}$ Cf. Parke, 1933: 44-45, que supone que fueron reclutados en la región y no en Tracia, de donde pasan por ser originarios los peltastas. Anderson, 1970: 303 n. 33, seguido por Cartledge, 1987: 211, estima que la cifra de tres mil peltastas es exagerada.

39 Prichett, 1971: 39-40; Krasilnikoff, 1992: 30-31.

${ }^{40}$ Para detalles y valoraciones de las campañas de Tibrón y Dercílidas, véase: Lewis, 1977: 139-141; Westlake, 1986; Cartledge, 1987: 208-211; Orsi, 2004: 43-50; Buckler, 2003: 39-58; Pascual González, 2007: 85-95. Sobre la defensa del territorio por Tisafernes: Lee, 2016: 275-278; Hyland, 2018: 129-132. 
presencia de mercenarios. El diarca euripóntida viajó con dos mil neodamodeis y seis mil aliados, además de un consejo asesor integrado por treinta espartiatas (X. HG. III 4.2-3 y Ages. 1.7; D.S. XIV 79.1; Plu. Ages. 6.1-5 y Lys. 23.1); Jenofonte dice que llevaba sitos para seis meses, lo que ha de entenderse como dinero (o plata) para pagar las raciones de comida durante ese tiempo, dado lo inviable de cargar con unos 30000 medimnoi de grano para alimentar a ocho mil hombres ${ }^{41}$. Ya en Éfeso, cuartel general de los lacedemonios en Asia, reunió a otros cuatro mil aliados (D.S. XIV 79.2) e hizo una proclama dirigida a las aristocracias grecoanatólicas para que se unieran a la campaña $o$, en su defecto, mandasen a un hombre armado y a caballo, medida con la que intentaba superar las carencias con respecto a la más numerosa y mejor entrenada caballería persa sin incurrir en cuantiosos gastos financieros (X. $H G$. III 4.15). Como la segunda opción fue preferida, en la práctica eso significó que el rey conseguía, sin necesidad de pagarlo, un cuerpo de caballería cuasimercenaria — según Diodoro (ibid.), cuatrocientos jinetes - y lo bastante competente como para acabar por imponerse a los persas en la batalla de Sardes ${ }^{42}$.

Fue presumiblemente también en Éfeso donde se le sumaron los antiguos cireos de Dercílidas, al mando de los cuales habría de poner al año siguiente a Herípidas (X. $H G$. III 4.20), miembro de su hetairia ${ }^{43}$ y hombre de su máxima confianza que desempeñó cargos de toda condición, siempre en el entorno del rey. En el relato jenofóntico los cireos no reaparecerán hasta la batalla de Coronea, donde, como tropas experimentadas, ocupan el centro de la formación y lanzan el importante ataque inicial que, seguido inmediatamente por la falange de Agesilao, rompe las filas de sus oponentes y los pone en fuga (X. $H G$. IV 3.15 y $17-$ 18).

Al lado de estos infantes pesados, Agesilao también dispuso de abundantes tropas ligeras mercenarias, porque cuando recibió el mandato de los éforos para regresar a Grecia —había estallado

\footnotetext{
${ }^{41}$ Krasilnikoff, 1993: 88-89.

42 Parke, 1933: 46; Marinovic, 1988: 41.

43 Agesilao desplegó una importante e intensa actividad de patronazgo, para la cual véase ahora Fornis, 2018, con la literatura científica anterior. Sobre lo pertinente de utilizar aquí

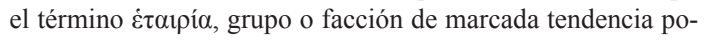
lítica e ideológica como los que existían en Atenas, remito a Luppino-Manes, 1991: esp. 255-256.
}

la guerra de Corinto- fueron los aliados minorasiáticos y los mercenarios los más dispuestos a seguirle, mientras los peloponesios mostraban un escaso entusiasmo por volver a casa para combatir a otros griegos. Para incentivarlos y al mismo tiempo intensificar su entrenamiento prometió que, una vez pasaran al continente europeo, en el Quersoneso tracio, recompensaría a las ciudades y a los capitanes mercenarios que se unieran con los contingentes mejor equipados y preparados de hoplitas, arqueros, peltastas y jinetes. Los premios consistían en armas finamente elaboradas y ornamentadas, así como coronas de oro, por un valor total no inferior a cuatro talentos (X. $H G$. IV 2.4-8). En la batalla de Coronea Jenofonte nos confirma que Agesilao disponía de muchos más peltastas que el enemigo ( $H G$. IV 3.16$)^{44}$.

Todos estos varios millares de mercenarios fueron sin duda pagados con los pingües beneficios obtenidos con el expolio y el saqueo sistemático al que Agesilao sometió las satrapías de Lidia, Frigia Helespóntica y Capadocia; el botín fue de tal magnitud que, según Jenofonte (Ages. 1.17-19), las cosas perdían su valor y se vendían por apenas nada; precisamente para comprar y vender esos bienes, obteniendo un sustancioso beneficio, Agesilao era acompañado por «una multitud que proveía un mercado para el saqueo» (D.S. XIV 79.2) ${ }^{45}$. En su regreso a Grecia, el rey todavía llevaba consigo mil talentos, puesto que, con el deseo de celebrar una victoria - no demasiado concluyente - en la batalla de Coronea ${ }^{46}$ quiso asistir a los juegos píticos que se desarrollaban en Delfos, participar en la pompe y consagrar al dios el diezmo del botín obtenido en Asia, no menos de cien talentos (X. HG. IV 3.21 y Ages. 1.34; Plu. Ages. 19.4). Sin ese botín la lealtad de los miles de mercenarios - $\mathrm{y}$ de los griegos de

\footnotetext{
${ }^{4}$ Aunque en la narrativa jenofóntica no parecen jugar un papel en el desarrollo de la batalla, Best, 1969: 84-85, sospecha que formaron parte de las tropas de choque en la acción de Herípidas.

${ }^{45}$ Como la marcha de Agesilao no parece tener objetivos estratégicos claros, Krasilnikoff, 1992: 32, también concluye que el saqueo era la principal amenaza para sus enemigos. Esto no es suficiente para Rop, 2019: 179, pero Hyland, 2018: 138, recuerda la sensibilidad de los nobles persas a los cuantiosos daños sufridos en sus propiedades.

${ }^{46}$ Coronea fue una victoria "técnica" de las armas espartanas (cf. Fornis, 2003: 151-156 para una reconstrucción y valoración de la batalla) que no trajo consigo una mejora de la situación en una Grecia central que, a excepción de Fócide y Orcómeno, seguía bajo la influencia del Estado federal beocio.
} 
Asia- quizá no hubiera sido la misma, como demuestra el ardid de Agesilao de transmitir a sus hombres como una victoria espartana las noticias de la importante derrota naval sufrida en Cnido, a fin de no minar su moral y evitar posibles deserciones: «se hizo a la idea de que la mayor parte del ejército era capaz de participar con gusto si le iban las cosas bien, pero si encontraban alguna dificultad no se veían obligados a tomar parte» (X. $H G$. IV 3.13; cf. Plu. Ages. 17.5).

Agesilao había recibido con desagrado la orden de los éforos de regresar a Grecia debido a que boicoteaba sus prometedores planes asiáticos (X. HG. IV 2.1-3 y Ages. 1.36). La victoria en la batalla del río Pactolo, librada cerca de Sardes en 395, había consolidado su poder en Esparta y potenciado su propaganda y su imagen panhelénicas. En ella el rey supo combinar con acierto la solidez y contundencia de los infantes pesados - entre los que debemos suponer se encontraban los mercenarios cireos - con la movilidad de los peltastas mercenarios y de la recién reclutada caballería profesional aportada por los aristoi minorasiáticos para imponerse a fuerzas enemigas superiores en número. Como consecuencia del choque, en el que el basileus obtuvo como botín setenta talentos más y amenazó con la captura de la capital lidia —incendió y saqueó sus alrededores durante tres días-, Artajerjes envió a Titraustes con la orden de decapitar a Tisafernes, ocupar su lugar y ofrecer la autonomia a los griegos asiáticos si pagaban el antiguo tributo, propuesta que fue rechazada por Agesilao (X. $H G$. III 4.20-25; Hel. Oxy. 11-12.1; D.S. XIV 80; cf. X. Ages. 1.2935; Plu. Ages. 10.1-8; Nep. Ages. 3.4-5; Paus. III 9.5-6; Polyaen. II 1.9; VII 16.1; Front. I 8.12) ${ }^{47}$.

En Occidente Esparta cuenta con un importante aliado en la figura de Dionisio el Viejo, que como en el pasado necesita de la pericia y la cualificación militar espartana - el epiphanos Aristo, también llamado Aretes (D.S. XIV 10.2-3, 70.3), y el jefe de mercenarios Aristóteles (D.S. XIV 78.1-2) contribuyeron a afianzar su régimen unipersonal, aunque el segundo acabó por ser de-

\footnotetext{
${ }^{47}$ No podemos entrar aquí en el análisis minucioso de las diferentes $-\mathrm{y}$ por momentos contradictorias - versiones ofrecidas por Jenofonte por un lado y el anónimo de Oxirrinco y Diodoro por otro. La historiografía moderna tiende a restar importancia a la batalla de Sardes, calificada más bien de escaramuza: Anderson, 1970: 118-119; Cartledge, 1987: 215-217; Hamilton, 1991: 97-100; Wylie, 1992; Shipley, 1997: 156163; Buckler, 2003: 64-69; Lotz, 2016.
}

vuelto a Esparta en 396 para ser juzgado por los disturbios que causaba - , pero ahora en abundancia y con celeridad. En el contexto de esta colaboración, en 398 los éforos espartanos permiten al tirano siracusano reclutar cuantos mercenarios lacedemonios deseara para su segunda guerra contra Cartago (D.S. XIV 44.2), sin duda entre los no ciudadanos (inferiores, neodamodeis, periecos), ya que en lugar de los atrasos en la soldada recibieron finalmente buenas tierras donde asentarse en Leontinos (D.S. XIV 78.2-3); la situación se repitió en 396 con el enrolamiento de otros mil más (D.S. XIV 58.1) y con el envío ese mismo año de treinta naves que, a las órdenes de Farácidas, participaron en la tercera guerra cartaginesa, con Siracusa asediada por los púnicos y el pueblo al borde de la revuelta, que no llega finalmente a cristalizar gracias a una decisiva intervención verbal de Farácidas (D.S. XIV 62.1, 63.4, 70.1-2) ${ }^{48}$. Pasaría una década antes de que Dionisio pudiera devolver el favor a los lacedemonios. Lo haría en 387 , bajo la forma de veinte naves que dieron a los lacedemonios la superioridad sobre los atenienses en el Helesponto en el momento en que se decidía la suerte de la guerra corintia (X. $H G$. V 1.26) ${ }^{49}$.

Precisamente la guerra corintia, que enfrentó a Esparta con una poderosa coalición integrada por Beocia, Corinto, Argos y Atenas, financiada por un Gran Rey persa que sacaba ventaja de los enemigos que los espartanos habían dejado atrás, supuso una década (395-386 a. C.) de conflicto extenuante, panhelénico, diez años que, sumados a los veintisiete de guerra del Peloponeso, dejaron una Hélade exhausta. Fue una guerra de desgaste y de "trincheras", con saqueos continuados y a gran escala, y que tuvo en el elevado coste económico consumido por guarniciones y mercenarios el principal gravamen para los contendientes ${ }^{50}$. Pero también en una gran batalla hoplítica como Coronea Esparta utilizó mercenarios, los cireos, que ya hemos comentado que, a las órdenes de Herípidas, lanzaron el asalto inicial (X. $H G$. IV

48 Sobre si hay que identificar o no a este personaje con el Fárax que ejerce de navarco en Jenofonte ( $H G$. III 2.12), junto a una evaluación de la implicación espartana en Sicilia, véase ahora Bearzot, 2018.

${ }^{49}$ Y volvería a hacerlo en los aciagos tiempos que siguieron a la débâcle de Leuctra, cuando el tirano les suministró más de veinte naves y dos mil mercenarios celtas e iberos, con la paga de cinco meses por adelantado (X. HG. VII 1.20-22 y 28-32; D.S. XV 70.1).

${ }^{50}$ Fornis, 2007b. 
3.15 y 17$)^{51}$. Poco después, en un conocido pasaje (IV 4.14), Jenofonte explica que ambos bandos ya no combatían con ejércitos cívicos, sino que recurrían cada vez en mayor medida a mercenarios.

A manos de una fuerza de peltastas mercenarios - no menos de dos mil, altamente cualificados y muy bien pagados con dinero per$\mathrm{sa}$ - comandados por el ateniense Ifícrates, en coordinación con la falange hoplítica dirigida por Calias, habría de sufrir Esparta una de las derrotas más dolorosas de toda su larga historia forjada en los campos de batalla: la aniquilación de casi la mitad de los hoplitas integrantes de la mora acantonada en el puerto corintio de Lequeo, 250 preciosas vidas lacedemonias (X. HG. IV 5.11-18; cf. D. XIII 22; Din. I 75; D.S. XIV 91.2-3; Polyaen. III 9.49 y $54 ;$ Nep. Iphicr. 2.3$)^{52}$. A la magnitud del desastre $(\pi \alpha ́ \theta 0 \varsigma)$ militar y humano, Plutarco añade la humillación pública porque «hoplitas hubieran sido vencidos por peltastas y lacedemonios por mercenarios» $\left(\right.$ Ages. 22.4) ${ }^{53}$.

Dercílidas y Agesilao habían empleado peltastas tracios y paflagonios de modo efectivo en labores de pillaje y saqueo durante sus expediciones asiáticas. Y los comandantes lacedemonios que operaron en la guerra corintia, sobre todo en el Egeo y la costa de Asia Menor, continuaron haciéndolo. En la ofensiva espartana del año 391, tras el fracaso de las negociaciones de paz, Tibrón dispuso de ocho mil soldados - mercenarios en su mayoría, si no en su totalidad—, además de levas locales, para liberar algunas ciudades (Éfeso, Priene, Magnesia, Leucofris) y llevar a cabo un saqueo sistemático del valle del Meandro, hasta que en una de las acciones es sorprendido y muer-

${ }^{51} \mathrm{Si}$ creemos a Polieno (III 9.45), al menos algunos de los cireos seguirían operativos y al servicio de Esparta dos años después, en la batalla por los Muros Largos que unían Corinto con su puerto de Lequeo; ni Jenofonte (HG. IV 4.8-9) ni Diodoro (XIV 86.3-4) registran mercenarios entre las fuerzas de que dispuso Praxitas, el polemarco de la mora instalada en Sición. Cartledge, 1987: 321 y Millender, 2006: 245, aceptan la noticia del polemólogo, mientras Bettalli, 2013: 154, n. 14, la considera poco fiable.

${ }^{52}$ Con esta y otras acciones similares, Ifícrates se aseguró una fama perenne y el paso a los anales de la historia militar como uno los comandantes griegos más innovadores, audaces y eficaces. Sobre su actuación en la guerra corintia, véase Fornis, 2004; Sekunda y Burliga, 2014: 7-48 et passim.

${ }^{53}$ En el erudito de Queronea, como en Jenofonte, el episodio funciona como una retribución divina para castigar a un Agesilao exultante por sus recientes éxitos y el botín conseguido en la Corintia y por su úppıs con los embajadores tebanos (cf. Shipley, 1997: 265-272, esp. 268-269). to, junto a muchos de sus hombres, por la caballería del sátrapa Estrutas (X. HG. 4.8.17-19 y 22; D.S. 14.97.1-4 y 99.1-3). Dífridas, a quien se encomendó la misión de reunir lo que quedaba del ejército de Tibrón y reclutar nuevas tropas con las que seguir combatiendo a Estrutas, tuvo la fortuna de que cayera en sus manos la hija del sátrapa y su marido Tigranes, que viajaban hacia Sardes; el sustancioso dinero del rescate fue empleado por el harmosta en pagar la soldada de sus mercenarios y consolidar la ofensiva espartana en Jonia (X. $H G$. IV 8.21) $)^{54}$.

Pero Esparta, lastrada quizá por el peso de una tradición y de un ideario que la habían coronado como el Estado hoplítico par excellence ${ }^{55}$, no supo alcanzar la eficacia de Ifícrates en la utilización de este tipo de tropas ligeras mercenarias en choques en formación contra el enemigo - los peltastas de Agesilao en las batallas de Sardes y Coronea (X. $H G$. III 4.23-24; IV 3.15) parecen ejercer labores auxiliares, de distracción y de captura de botín-, como se infiere del siguiente episodio. En la primavera de 388, Ifícrates fue enviado al Helesponto al frente de ocho naves y mil doscientos de sus inseparables peltastas mercenarios, en su mayoría veteranos de las campañas en el istmo de Corinto, para evitar que el espartiata Anaxibio, harmosta de Abido, dañara una influencia ateniense en la región que Trasibulo de Estiria había construido con gran esfuerzo en los años anteriores. Después de hacerse la guerra mutuamente durante un tiempo a través de prácticas piráticas (leisteia), el traslado de Anaxibio acompañado de unos pocos lacedemonios del destacamento, mil misthophoroi eolios - presumiblemente infantes ligerosy doscientos hoplitas abidenos hasta la ciudad amiga de Antandro, en la que pretendía instalar una guarnición, proporcionó a Ifícrates la oportunidad de planear y tender una emboscada. Esta tuvo lugar cerca de Cremaste, en terreno abrupto y estrecho, donde era imposible que las tropas de Anaxibio, que avanzaban en una columna larga y estrecha, pudieran formar. Ifícrates atacó primero a los lacedemonios de la retaguardia, consiguió matar a todos ellos - un mínimo de doce-, Anaxibio incluido, y luego a unos doscientos mercenarios del centro de la columna - que por tener un equipamiento más ligero tenían más fácil la

${ }^{54}$ Sobre estas operaciones: Buckler, 2003: 154-156; Hyland, 2018: 161-163.

${ }^{55}$ Pace Bettalli, 2013: 148. 
huida - y a cincuenta hoplitas abidenos de los que se encontraban en vanguardia (X. $H G$. IV 8.33-39; Plu. Mor. 219C). En términos de geoestrategia, la audaz acción de Ifícrates contribuyó a salvar temporalmente el control ateniense del Helesponto, hasta que la ayuda persa y siracusana hizo posible que el navarco Antálcidas bloqueara la ruta ateniense de aprovisionamiento de grano póntico y pusiera fin a la contienda.

Antes de que Artajerjes nombrara a Tiribazo para la satrapía de Sardes y se materializara la asistencia económica persa, los espartanos tenían dificultades para pagar a sus nautai, que, en consecuencia, se negaban a remar. En 388 eso le sucedió a Eteónico, harmosta de Egina, pese a que los presionaba y obligaba. Los lacedemonios enviaron entonces a Teleutias, el hermanastro de Agesilao, quien reconoce a los marineros que no llega con dinero, aunque pronto logra disponer del suficiente como para adelantarles la paga de un mes gracias a la venta del botín conseguido en su osado ataque al Pireo y en los actos de piratería sobre pesqueros y barcos mercantes y de transporte que navegaban entre el puerto ateniense y el cabo Sunio. «Con ello mantenía las naves equipadas y a los marineros contentos y dispuestos para el servicio», le elogia Jenofonte ( $H G$. V 1.13-24).

La paz del Rey o paz de Antálcidas garantizó para los espartanos el papel de dirigentes

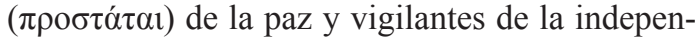
dencia ( $\alpha$ vovouí $\alpha$ ) de las ciudades, con el beneplácito de Persia; de hecho, los griegos se refirieron a ella como «la paz enviada por el Rey» ( $\dot{\eta}$ ưंò

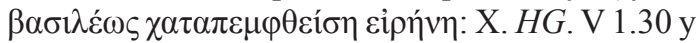
35; cf. D. XV 9, 29; XX 54; Plb. I 6.2). Esto significaba la legitimación del imperio lacedemonio, la autoridad para acallar cualquier atisbo o brote de oposición a su Machtpolitik. En el marco de esta

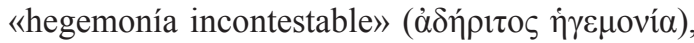
Esparta seguirá movilizando mercenarios de manera asidua y en proporciones significativas, con una evolución hacia un mayor empleo de tropas ligeras, principalmente para expediciones $\mathrm{y} / \mathrm{o}$ mantenimiento de guarniciones fuera del Peloponeso (Calcídica, Beocia, Corcira), pero también como apoyo a ejércitos de ciudadanos y aliados ${ }^{56}$. Sin duda fueron igualmente empleados en la flota, junto a los esclavos, a juzgar por el rechazo del

56 Parke, 1933: 83-90; Best, 1969: 97-101, 112-114; Anderson, 1970: 126-138; Hamilton, 1991: 174-199; Buckler, 2003: 235-239, 263-267; Bettalli, 2013: 159-161; Millender, 2006: 248-253; English, 2012: 90-99. demos ateniense - convencido por Cefisódotoa ejercer el mando en el mar mientras los espartanos lo hacen en tierra, en el marco de una alianza que en 369 les unía frente a los tebanos; no es justo, dice Cefisódoto, que los atenienses dirijan una flota a la que los espartanos contribuyen con hilotas y mercenarios, lo más despreciable y ruin de la sociedad, en tanto que ellos aportaban excelentes hoplitas y caballeros al ejército terrestre conducido por Esparta (X. HG. VII 1.12-13). Y, por fin, una aislada referencia de Jenofonte en el Hipárquico (9.4) nos informa escuetamente de la presencia mercenaria en la caballería lacedemonia, que según el historiador ateniense mejoró tras su introducción (es conocida su sentencia en $H G$. VI 4.10 de que en Esparta nunca fue un cuerpo de prestigio formado por la elite social, como sucede en otros Estados, sino un cuerpo desacreditado en el que acababan los peores combatientes y que nunca cumplió un papel glorioso).

Una innovación importante se produjo en 382 , en los prolegómenos de la dura guerra contra la liga calcídica. Con el objetivo de superar el creciente desencanto de los aliados por servir en campañas que prácticamente solo interesaban al hegemon y al mismo tiempo para mejorar la eficacia del ejército con la contratación de profesionales de la guerra, Esparta introdujo en la liga del Peloponeso la posibilidad de que los aliados contribuyeran con dinero en lugar de con hombres

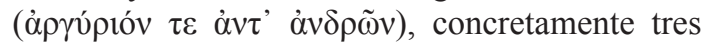
óbolos eginetas - equivalentes a cuatro óbolos y medio atenienses - por hoplita y día, la mitad por un infante ligero y el cuádruple por cada caballero (X. HG. V 2.21-23; D.S. XV 31.1-2). Como la medida tuvo buena acogida entre los aliados, estas cantidades compensatorias - razonables, pero no sustanciosas, excepto para los hippeis, cuyo coste parece elevado - iban a ofrecer en principio una nueva fuente de financiación para que los lacedemonios enrolaran soldados a sueldo más cualificados, motivados y a priori más eficaces que los proporcionados por los symmachoi ${ }^{57}$. La figura de

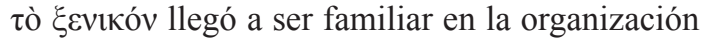
sociomilitar espartana de comienzos del siglo IV y así, por ejemplo, en la Lakedaimonion Politeia

\footnotetext{
${ }^{57}$ Véase el comentario sobre este scutagium —con paralelos medievales- a cargo de Bettalli, 2013: 156-158, quien sospecha (161-163) que, dada la precariedad de las finanzas públicas de las ciudades peloponésicas, serían los plousioi los encargados de hacer frente a semejante gasto; cf. también Krasilnikoff, 1993: 90 y Trundle, 2004: 94, 109.
} 
(10.3) Jenofonte alude a su reciente introducción en la realización de las guardias, una labor desempeñada hasta entonces por otros infantes ligeros (hamippoi), los esciritas.

Pese a todo, las campañas en que los lacedemonios contaron con mercenarios no fueron más efectivas por esa razón, sobre todo cuando implicaban a tropas ligeras. Sintomático es el episodio que tuvo lugar en ese mismo año 382, cerca de las murallas de Olinto: Teleutias lanzó a los peltastas pagados por el rey macedonio Amintas III y mandados por Tlemónidas, sin apoyo de los infantes pesados, contra la caballería olintia en aparente huida, pero los jinetes giraron repentinamente y atacaron a los peltastas dispersos, causando más de cien bajas, incluida la de su oficial Tlemónidas; pero lo peor estaba por llegar, ya que el desordenado contrataque de Teleutias, presa de las emociones, condujo a un desastre mayor en el que él mismo encontró la muerte, hecho que provocó la fuga de sus hombres en distintas direcciones y la muerte de muchos en el intento (X. $H G$. V 2.38; 3.3-6).

La derrota de Teleutias guarda similitud con la sufrida tres años después, en este caso en territorio beocio, por Fébidas, aquel oficial espartano que había perpetrado la toma de la Cadmea tebana («hombre que no pasaba por ser reflexivo e inteligente»: X. $H G$. V 2.28). Nombrado por Agesilao harmosta de la recién fortificada Tespias, Fébidas ejecutaba razias y expoliaba el territorio de los tebanos con la movilidad que otorga un contingente de peltastas mercenarios. Al sufrir un ataque de hoplitas y caballeros tebanos, inicialmente los hizo retroceder, acosándolos con sus peltastas y con apoyo de hoplitas tespieos - de poca fiabilidad y temerosos de los hoplitas tebanos-, pero, envalentonado, ordenó la persecución; cuando los caballeros tebanos se reagruparon y volvieron grupas, sorprendieron a los peltastas adelantados y dispersos y al propio Fébidas, cuya muerte provocó la desbandada de los mercenarios y luego la de los muy rezagados hoplitas tespieos, muriendo algunos antes de poder refugiarse dentro de las murallas (X. $H G$. V 4.41-45; las pérdidas lacedemonias son más elevadas en D.S. XV 33.6 y Polyaen. II 5.2, según el cual, por cierto, Górgidas era el jefe del escuadrón de caballería tebana).

La compensación pecuniaria en lugar de la contribución en hombres fue entregada por los бú $\mu \mu \alpha \chi 01$ de Esparta para la campaña contra Corcira, conducida en 372 por el navarco Mnasipo, al que acompañaban no menos de 1500 mercenarios.
La depredación sobre la isla - rica en cultivos, esclavos y ganado - emprendida por las fuerzas de Mnasipo satisfacía con creces todas las necesidades de los sitiadores. Pese a esta situación favorable, y a que no le faltaba dinero porque los aliados habían aportado en mayor medida al tratarse de una expedición naval, llevado de la avaricia el navarco licenció a algunos mercenarios sin pagarles, mientras que a otros les adeudaba el sueldo de dos meses; Jenofonte atribuye la subsiguiente derrota y muerte de Mnasipo al desánimo y el odio que cundió entre sus soldados, «que es lo menos conveniente para una batalla» (X HG. VI 2.3-23).

Solo Agesilao, según un Jenofonte que no es un modelo de imparcialidad, parece no haberse desenvuelto del todo mal en la dirección de peltastas mercenarios combinados con hoplitas y caballeros durante la invasión y saqueo de territorio tebano en 378 , en medio de fosos y empalizadas utilizadas para atrincheramiento; los peltastas, necesarios para ocupar el monte Citerón y luego pasar a la llanura beocia, los tuvo que "tomar prestados" de la ciudad arcadia de Clitor, para lo cual el rey tuvo que interrumpir la guerra que esta mantenía con su vecina Orcómeno - imponiendo el liderazgo espartano en la liga del Peloponeso-

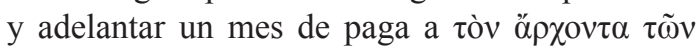

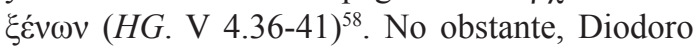
(XV 32; cf. Nep. Chabr. 1) cuenta que, en esta misma campaña, en la que disponía de un imponente ejército de 18000 hombres y 1500 caballeros, rehusó el combate contra los mercenarios de Cabrias apostados, junto a los hoplitas tebanos, en una posición elevada, «admirado de la disciplina de los enemigos y de su actitud de desprecio ... permaneciendo firmes en sus puestos, con los escudos apoyados contra sus rodillas y las lanzas apuntando al adversario»; el rey espartano se replegó y prefirió volver a su actividad preferida,

58 Poco antes, había sido Cleómbroto quien, en su primera campaña al frente del ejército lacedemonio, había conducido la invasión de Beocia; llevó a sus peltastas a través del monte Citerón y cogió por sorpresa a Cabrias, apostado de guardia con una unidad de 150 peltastas en el camino de Eleuteras, matando a casi todos ellos (X. HG. V 4.14), si bien después parece haber mostrado una cierta pasividad y no sacó partido de la situación - el rey agíada no compartía la aversión por los tebanos de Agesilao-, razón por la cual su colega en el trono lideró la siguiente expedición (V 4.35). En 376 Cleómbroto intentó repetir la táctica, pero atenienses y beocios estuvieron más vigilantes y les tendieron una embocada en la que mataron a cuarenta peltastas (V 4.49). 
devastar y someter a pillaje la llanura, obteniendo un sustancioso botín.

Como conclusión podemos decir que durante el período de su hegemonía el Estado lacedemonio utilizó masivamente en sus campañas tanto mercenarios como grupos dependientes ante la evidente y cruda realidad de que precisaba abundante mano de obra militar para atender las necesidades de su ambicioso programa imperial, mientras los cada vez más mermados numéricamente homoioi se reservaban la gestión y administración de una arche de la que eran los principales beneficiarios. Los periecos, cuyo porcentaje no había dejado de crecer en el ejército lacedemonio desde inicios del siglo $\mathrm{V}^{59}$, ya no eran suficientes. Por su parte, los aliados mostraban una creciente desafección al comprobar que los espartanos se arrogaban la explotación de los beneficios del imperio; desde la victoria sobre Atenas en 404, la liga del Peloponeso fue resquebrajándose sin cesar hasta desaparecer de facto en la década de 360.

La derrota frente a los tebanos en la batalla de Leuctra, donde la participación mercenaria - comandada por un espartiata, Hiarón, que tiene estatuas en Olimpia y Delfos (X. HG. VI 4.9; Plu. Mor. 397F; $I v O \mathrm{n}^{\circ} 274$ ) - no tuvo ninguna incidencia y perdieron la vida cuatrocientos de los setecientos espartiatas combatientes (X. $H G$. VI 4.15), aproximadamente un tercio de los ciudadanos de pleno derecho, pondría en evidencia la fragilidad de las costuras que habían hilvanado este imperio continental y naval, con teatros bélicos cada vez más lejanos ${ }^{60}$. Tras la pérdida de Mesenia, a no ser que poseyeran tierras en Laconia, los espartiatas que tenían allí sus parcelas se vieron despojados de su medio de subsistencia, cayendo en la miseria y perdiendo los derechos de ciudadanía; el mercenariado se convertirá en la única alternativa "digna" para lograr ingresos, lo que no les diferenciaba ya de periecos y otros grupos dependientes. Este camino irreversible hacia la plutocracia ${ }^{61}$, en medio del desmoronamiento del régimen licurgueo, explica el creciente número de lacedemonios sirviendo como mercenarios para otros Estados a lo largo del siglo IV y el que la región del Ténaro se consolide como un gran mercado de mercenarios del Mediterráneo orien-

59 Últimamente Stewart, 2018: 377-378 y Ducat, 2018: 601-603; solo Lazenby, 1985 y Hawkins, 2011: 14-17 rechazan con fuerza esta idea.

${ }^{60}$ En el mismo sentido, Millender, 2006: 253.

${ }^{61}$ Cf. Hodkinson, 2000: esp. 432-441. tal. La situación se había invertido de tal modo que incluso reyes de descendencia heraclida como Agesilao II o Arquidamo III acabaron sus días como xenikoi strategoi de dinastas extranjeros, presumiblemente en un intento de captar fondos con los que contratar a su vez, en una suerte de paradoja que se alimenta circularmente, tantos mercenarios como fuera posible para su fútil empresa de reconquistar Mesenia (X. Ages. 2.25-27; D.S. XVI 88.3; Plu. Ages. 36-40) ${ }^{62}$.

\section{BIBLIOGRAFÍA}

Alfieri Tonini, T. (1975): «Il problema dei "neodamodeis" nell'ambito della società spartana». Rendiconti Istituto Lombardo, 109: 305-316.

Anderson, J. K. (1970): Military Theory and Practice in the Age of Xenophon. Berkeley, University of California Press.

Bassett, Sh. (2001): «The Enigma of Clearchus the Spartan». Ancient History Bulletin, 15.1-2: 1-13.

Bearzot, C. (2018): «Il navarco Farace/Faracida e la politica occidentale di Sparta», M. Intrieri (ed.), Koinonia. Studi di storia antica offerti a Giovanna De Sensi Sestito. Roma, Giorgio Bretschneider Editore: 479-496.

Bertosa, B. (2005): «The Social Status and Ethnic Origin of the Rowers of the Spartan Triremes». War \& Society, 23.1: 1-20. https://doi. org/10.1179/072924705791202265

Best, J. P. G. (1969): Thracian Peltasts and their Influence on Greek Warfare. Groningen, WoltersNoordhoff.

Bettalli, M. (2013): Mercenari. Il mestiere delle armi nel mondo greco antico. Roma, Carocci.

Bleckmann, B. (1993): «Sparta und seine Freunde im Dekelischen Krieg. Zur Datierung von $I G$ V 1,1». Zeitschrift für Papyrologie und Epigraphik, 96: 297-308.

Bleckmann, B. (2002): «Nochmals zur Datierung von IG V 1,1». Ktèma, 27: 35-38.

Bruni G. G. (1979): «Mothakes, Neodamodeis, Brasideioi», M. Capozza (ed.), Schiavitù, manomissione e classi dependenti nel mondo antico. Roma, L'Erma di Bretschneider: 21-33.

Buckler, J. (2003): Aegean Greece in the Fourth Century B.C. Leiden, Brill.

Carlier, P. (1994): «Les Inférieurs et la politique extérieure de Sparte», M.-M. Mactoux, E. Geny (eds.),

${ }^{62}$ Sobre el Agesilao mercenario: Cartledge, 1987: esp. 325-329; Bettalli, 2013: 165-169; Rop, 2019: 108-115. Para la expedición de Arquidamo en apoyo de los tarentinos: Nafissi, 2004, y Bettalli, 2013: 169-171. 
Mélanges Pierre Lévêque, VIII. Besançon, Université de Franche-Comté: 25-41.

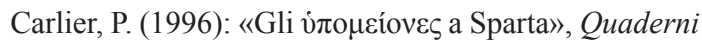
dell'Istituto di Archeologia e Storia Antica, 5: $27-$ 31.

Cartledge, P. A. (1987): Agesilaos and the Crisis of Sparta. Baltimore, The Johns Hopkins University Press.

Christien-Tregaro, J. (1993): «Les bâtards spartiates», M.-M. Mactoux, E. Geny (eds.), Mélanges Pierre Lévêque, VII. Besançon, Université de FrancheComté: 33-40.

Couvenhes, J.-Chr. (2008): «Le Ténare: un gran marché de mercenaires à la fin du IV ${ }^{\mathrm{e}}$ siècle?», C. Grandjean (ed.), Le Péloponnèse d'Epaminondas à Hadrian. Bordeaux, Ausonius: 279-315.

Cozzoli, U. (1978): «Sparta e l'affrancamento degli iloti nel 5 e 4 sec.». Miscellanea Greca e Romana, 6: 213-232.

Doran, T. (2018): Spartan Oliganthropia. Leiden, Brill.

Ducat, J. (2006): Spartan Education. Youth and Society in the Classical Period. Swansea, Classical Press of Wales.

Ducat, J. (2018): «The Perioikoi», A. Powell (ed.), A Companion to Sparta. Hoboken, Blackwell: 596614.

Ducrey, P. (2019): Polemica. Études sur la guerre et les armées dans la Grèce ancienne. Paris, Les Belles Lettres.

English, S. (2012): Mercenaries in the Classical World. Barnsley, Pen and Sword.

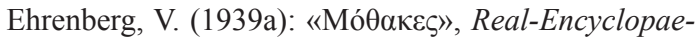
die, XVII-1: 382-384.

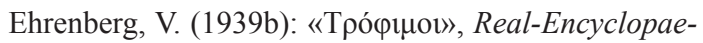
die, VII A-1: 675-679.

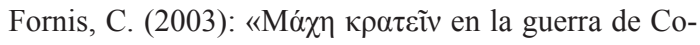
rinto: las batallas hoplíticas de Nemea y Coronea (394 a.C.)». Gladius, 23: 141-159. https://doi. org/10.3989/gladius.2003.48

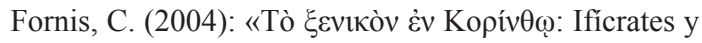
la revolución subhoplítica». Habis, 35: 71-86.

Fornis, C. (2007a): «La conspiración de Cinadón: ¿paradigma de resistencia de los dependientes lacedemonios?». Studia Historica (Historia Antigua), 25: 103-115.

Fornis, C. (2007b): «Campañas espartanas olvidadas: Jenofonte y la fase de desgaste de la guerra de Corinto». Ktèma, 32: 351-361.

Fornis, C. (2018): «El poco espartano patronazgo de Agesilao», J. Pascual, B. Antela-Bernárdez, D. Gómez Castro (eds.), Cambio y pervivencia. El mundo griego en el siglo IV a.C. Madrid, Ediciones Universidad Autónoma de Madrid: 125-140.

Furuyama, M. (1991): «Minor Social Groups in Sparta: Mothakes, Trophimoi and Nothoi of Spartiatai». Kodai, 2: 1-20.
Hamilton, Ch. D. (1991): Agesilaus and the Failure of Spartan Hegemony. Ithaca-London, Cornell University Press.

Hawkins, C. (2011): «Spartans and Perioikoi: the Organization and Ideology of the Lakedaimonian Army in the Fourth Century B.C.». Greek, Roman, and Byzantine Studies, 51: 401-434.

Hodkinson, S. (1997): «Servile and Free Dependants of the Classical Spartan "Oikos"», M. Moggi, G. Cordano (eds.), Schiavi e dipendenti nell'ambito dell'«oikos» e della «familia». Pisa, Edizioni ETS: 45-71.

Hodkinson, S. (2000): Property and Wealth in Classical Sparta. London-Swansea, Duckworth-Classical Press of Wales.

Humble, N. (2004): «Xenophon's Sons in Sparta? Perspectives on Xenoi in the Spartan Upbringing», Th. J. Figueira (ed.), Spartan Society. Swansea, Classical Press of Wales: 231-308.

Hunt, P. (1998): Slaves, Warfare, and Ideology in the Greek Historians. Cambridge, Cambridge University Press.

Hyland, J. O. (2018): Persian Interventions. The Achaemenid Empire, Athens, and Sparta, 450-386 BCE. Baltimore, The Johns Hopkins University Press.

Kallet, L. (2001): Money and the Corrosion of Power in Thucydides. The Sicilian Expedition and Its Aftermath. Berkeley, University of California Press.

Krasilnikoff, J. A. (1992): «Aegean Mercenaries in the Fourth to Second Centuries B.C. A Study in Payment, Plunder and Logistics of Ancient Greek Armies». Classica et Mediaevalia, 43: 23-36.

Krasilnikoff, J. A. (1993): «The Regular Payment of Aegean Mercenaries in the Classical Period». Classica et Mediaevalia, 44: 77-95.

Lazenby, J. F. (1985) The Spartan Army. Warminster, Aris \& Philllips.

Lee, J. W. I. (2016): «Tissaphernes and the Achaemenid Defense of Western Anatolia, 412-395 BC», J. Armstrong (ed.), Circum Mare: Themes in Ancient Warfare. Leiden, Brill: 262-281.

Lengauer, W. (1979): Greek Commanders in the 5th and 4th Centuries B.C. Politics and Ideology: A Study of Militarism. Warsaw, Warsaw University Press.

Lewis, D. M. (1977): Sparta and Persia. Leiden, Brill. Loomis, W. T. (1992): The Spartan War Fund: IG V,1,1 and a New Fragment, Historia Suppl. 74. Stuttgart, Franz Steiner.

Lotz, H. (2016): «Die 'Schlacht bei Sardeis' 395 v. Chr. Ein historiographisches Konstrukt?». Historia, 65: 126-154.

Lotze, D. (1962): «Móthakes». Historia, 11: 427-435.

Luppino-Manes, E. (1991): «I pí̉or di Agesilao». Ktèma, 16: 255-262.

Luraghi, N. (2006): «Traders, Pirates, Warriors: The Proto-History of Greek Mercenary Soldiers in the Eastern Mediterranean». Phoenix, 60: 21-47. 
MacDowell, D. M. (1986): Spartan Law. Edinburgh, Scottish Academic Press.

Marinovic, L. (1988): Le mercenariat grec au IVe siècle avant notre ère et la crise de la polis. Besançon, Université de Franche-Comté.

Millender, E. (2006): «The Politics of Spartan Mercenary Service», S. Hodkinson, A. Powell (eds.), Sparta \& War. Swansea, Classical Press of Wales: 235-266.

Miller, H. F. (1984): «The Practical and Economic Background to the Greek Mercenary Explosion». Greece \& Rome, 31.2: 153-160. https://doi. org/10.1017/s0017383500028527

Nafissi, M. (2004): «Sparta, Taranto e la spedizione di Archidamo», Alessandro il Molosso e i condottieri in Magna Grecia, Atti del 43 Convegno di Studi sulla Magna Grecia (Taranto-Cosenza, 26-30 settembre 2003). Taranto: 181-195.

Ogden, D. (1996): Greek Bastardy in the Classical and Hellenistic Periods. Oxford, Oxford Clarendon Press.

Orsi, D. P. (2004): «Sparta e la Persia: la guerra in Asia, 400-394 a.C.». Incidenza dell'Antico, 2: 41-58.

Paradiso, A. (1997): "Gli iloti e 1'“oikos"», in M. Moggi, G. Cordano (eds.), Schiavi e dipendenti nell'ambito dell'«oikos»e della «familia». Pisa, Edizioni ETS: 73-90.

Parke, H. W. (1930): «The Development of the Second Spartan Empire (405-371 B.C.)». Journal of Hellenic Studies, 50: 37-79. https://doi. org/10.2307/626162

Parke, H. W. (1933): Greek Mercenary Soldiers from Earliest Times to the Battle of Ipsus. Oxford, Oxford Clarendon Press.

Pascual González, J. (2007): «Intervención militar en Asia Menor y política interna en Esparta (400-395 a.C.)». Polis. Revista de ideas y formas políticas de la Antigüedad Clásica, 19: 77-112.

Piérart, M. (1995): «Chios entre Athènes et Sparte. La contribution des exilés de Chios à l'effort de guerre lacédémonien pendant la Guerre du Péloponnèse. $I G \mathrm{~V}, 1,1+(S E G$ XXXIX 370)». Bulletin of Correspondance Hellénique, 119: 253-282. https://doi. org/10.3406/bch.1995.1648
Pritchett, W. K. (1971): The Greek State at War, I. Berkeley, University of California Press.

Rop, J. (2019): Greek Military Service in the Ancient Near East, 401-330 BCE. Cambridge, Cambridge University Press.

Roy, J. (1967): «The Mercenaries of Cyrus». Historia, 16: $287-323$.

Roy, J. (2004): «The Ambitions of a Mercenary», R. Lane Fox (ed.), The Long March. Xenophon and the Ten Thousand. New Haven, Yale University Press: 264-288.

Ruzé, F. (1993): «Les inférieurs libres à Sparte: exclusion ou integration?», M.-M. Mactoux, E. Geny (eds.), Mélanges Pierre Lévêque, VII. Besançon, Université de Franche-Comté: 297-310.

Sealey, R. (1976): «Die spartanische Nauarchie». Klio, 58: 335-358. https://doi.org/10.1524/ klio.1976.58.12.335

Sekunda, N. V. y Burliga, B. (eds.) (2014), Iphicrates, Peltasts and Lechaeum. Gdansk, Foundation for the Development of Gdańsk University.

Shipley, D. R. (1997): Plutarch's Life of Agesilaos. Response to Sources in the Presentation of Character. Oxford, Oxford Clarendon Press.

Stewart, D. (2018): «From Leuktra to Nabis, 371-192», A. Powell (ed.), A Companion to Sparta. Hoboken, Blackwell: 374-402.

Tourraix, A. (1999): «Les mercenaires grecs au service des Achéménides», P. Brun (ed.), Guerres et sociétés dans les mondes grecs (490-322 av. J.-C.). Paris, Armand Colin: 201-216.

Trundle, M. (2004): Greek Mercenary: From the Late Archaic Period to Alexander. London, Routledge.

Valzania, S. (1999): Brodo nero. Sparta pacifica, il suo esercito, le sue guerre. Roma, Jouvence.

Welwei, K.-W. (1974): Unfreie im antiken Kriegsdienst I, Athen und Sparta. Wiesbaden, Franz Steiner.

Westlake, H. D. (1986): «Spartan Intervention in Asia, 400-397 B.C.». Historia, 35: 405-426.

Willets, R. F. (1954): «The Neodamodeis». Classical Philology, 49: 27-32. https://doi. org/10.1086/363718

Wylie, G. (1992): «Agesilaus and the Battle of Sardis». Klio, 74: 118-130. https://doi.org/10.1524/ klio.1992.74.74.118 
